\title{
Study on Prevalence and Economic Significance of Bovine Hydatidosis in Bako Muncipal Abattoir, West Shoa Zone, Oromiya Regional State
}

\section{Berihu Haftu* and T}

Department of Animal Science, Adigrat University, Ethiopia

\begin{abstract}
A cross-sectional study aimed at determining the prevalence and cyst characteristics and estimating the financial loss due to cystic echinococcosis (hydatidosis) in cattle slaughtered at Bako municipal abattoir was conducted from November 2011 to April 2012. Out of 246 cattle examined, 29 (11.88\%) were found to harbor visible hydatid cysts. Significantly higher infection was detected in cattle's with poor body conditions $(P<0.05)$ than animals with medium and good body condition score. No significant variation was observed with regard to sex of animals. Regarding organ distribution, infections of the lung, liver, kidney, and spleen and heart were $47.2 \%, 38.88 \%, 8.33 \%$, and $2.77 \%$ respectively. Of the total 36 hydatid cysts counted, $17(47 \%), 14(38.88 \%)$, and $5(13.88 \%)$ were found to be small-sized, medium-sized, and large-sized, respectively. Likewise, out of 36 cysts assessed, $18(50 \%)$ were fertile, $4(11.11 \%)$ sterile, and $14(38.88 \%)$ calcified. Of the 29 fertile cysts subjected for viability test, $12(27.77 \%)$ were viable while $8(22.22 \%)$ were nonviable. Moreover, assessment of annual economic loss due to bovine hydatidosis at Bako municipal abattoir from offal condemnation and carcass weight loss was estimated at 180,792 ETB (Ethiopian Birr). Despite the moderate magnitude of infection detected currently, there seems to be an existing socioeconomic situation favorable for hydatidosis, and hence, it remains one of the most important diseases warranting serious attention for prevention and control actions in Bako district. Hence, establishment of well-equipped standardized abattoirs, creation of public awareness, and control of stray dogs are of paramount importance.
\end{abstract}

Keywords: Hydatidosis; Prevalence; Economic significance; Ethiopia

\section{Introduction}

Echinococcosis (Hydatidosis) is a chronic cyst-forming parasitic helminthic disease of domestic and wild ungulates as well as human beings caused by infection with the larval (metacestode) stages of dog tapeworms belonging to the genus Echinococcus and family Taeniidae. Three broad morphological forms of echinococcosis are recognized clinically: cystic echinococcosis caused by $E$ granulosus, alveolar echinococcosis caused by $E$ multilocularis, and polycystic echinococcosis caused by Echinococcusvogeli or Echinococcusoligarthrus [1]. The life cycle of Echinococcus species is complex, involving two hosts (definitive hosts and intermediate hosts) and a free-living egg stages. Dogs are the usual definitive hosts whilst a large number of mammalian species can be intermediate hosts, including domestic ungulates and man.

The disease occurs throughout the world and causes considerable economic losses and public health problems in many countries including Ethiopia [2]. The public health and economic significances of hydatidosis lies on the cost of hospitalization, medical and surgical fees, loss of income and productivity, permanent or temporary incapacity to work social consequence hydatidosis of disability and mortality [3]. In food animal hydatidosis has an adverse effect on production causing decreased production of meat, milk, wool, reduction in growth rate and predisposition to other diseases. The distribution of the disease varies depending on the cause; E. granulosus has a global distribution; E. multilocularis occurs in wide areas of the Northern Hemisphere, E. shiquicus is found in the People's Republic of China and E. oligarthrus and E. vogeli are confined to Central and South America [4]. Cystic Echinococcosis is still endemic in cattle herding areas of the world and is a public health problem in Mediterranean, Middle East, Asia, South America and Africa, including Ethiopia [5].

Diagnosis of the disease relies on epidemiologic and clinical findings; on detection of the hydatid cyst by imaging techniques, and serology. There are several major options for treatment of Cystic echinococcosis (CE), including surgery, puncture aspiration injection reaspiration (PAIR), and chemotherapy [6].

In Ethiopia, the presence and prevalence of Hydatidosis (Echinococcosis) is well established. The information existing from different authors confirms that the disease is prevalent in various parts of the country; kebede et al. [7] 22.1\%, and Berhe [8] 32.1\% are some of the researches conducted in different parts of the country to determine the prevalence and economic impact of the disease. And from these data's it can be deduced that it is most commonly observed in bovine species.

Despite the above studies, in Ethiopia, the disease has not been investigated sufficiently, and information related to its prevalence and economic impact is still limited especially in and around the study area (Western Shoa, Bako). Bako is the smallest town, where a large population of cattle is reared with different husbandry system in and around the area. It is assumed that the problem (Hydatidosis) is a challenge in the study area like the other parts of the country and with this hypothesis the main objective of this study were:

- To assess the overall prevalence of the diseases and

- To investigate the effects of risk factors on prevalence of the disease

*Corresponding author: Berihu Haftu, Department of Animal Science, Adigrat University, Ethiopia, Tel: +251-913-173312; E-mail: berihu.haftu@yahoo.com

Received September 08, 2014; Accepted November 17, 2014; Published November 20, 2014

Citation: Haftu B, Kebede T (2014) Study on Prevalence and Economic Significance of Bovine Hydatidosis in Bako Muncipal Abattoir, West Shoa Zone, Oromiya Regional State. J Veterinar Sci Technol 5: 197. doi:10.4172/21577579.1000197

Copyright: ( 2014 Haftu B, et al. This is an open-access article distributed under the terms of the Creative Commons Attribution License, which permits unrestricted use, distribution, and reproduction in any medium, provided the original author and source are credited. 
- To know the prevalence of the diseases at organ level and

- To overview the economic significance of haydatidosis.

\section{Material and Methods}

\section{Description of the study area}

The study was conducted in Bako municipality abattoir, from November 2011 to April 2012 Which is situated in Western Shoa zone, Oromia regional state, around $281 \mathrm{~km}$ away West of Addis Ababa. The area is found at a longitude of $908 \mathrm{~N}$ and latitude of $3703 \mathrm{E}$ and the altitude range is from 1600 to 2000 meters above sea level. It has an annual rainfall of $1200 \mathrm{~mm}, 89 \%$ of which falls between May and September and temperature ranging from and $22-31^{\circ} \mathrm{C}$ with average temperature of $27^{\circ} \mathrm{C}$. The rainfall is bi-modal with the short rain coming in March and April, there is district dry season extending usually November to February. Agriculture is the main occupation of the population of the area. The agricultural activities are mainly mixed type with cattle rearing and crop production under taken side by side. Extensive system of livestock management predominate the area and dogs are rarely used for control and guarding of herds of cattle and flocks of sheep and goats, which is related to religious taboos and social norm [2].

\section{Study design and study animals}

A cross sectional observational study method were carried out to assess the prevalence and economic significance of hydatid cyst in slaughtered cattle in Bako municipality abattoir and a total of 246 indigenous zebu cattle slaughtered during the study period were included in the study. During ante-mortem examination each study animal was given an identification number; and age was determined.

During this study the age of the animals brought for slaughter was determined by examination of the teeth eruption according to. All cattles slaughtered during the study were adult. It was difficult to precisely indicate the geographical origin of all animals slaughtered at the abattoir and relate the findings on hydatidosis to a particular locality. Nevertheless, the attempts made in this regards have disclosed that the majority of them were drawn from market oriented areas (Shoboka, Jere, and Bako markets). Both sex group of the cattle were presented for slaughtering, but males were higher in number, so, infection rate regarding sex variation was included.

\section{Sample Size and Sampling Method}

The sample size was calculated according to Thrusfield [9] by considering $20 \%$ expected prevalence and $5 \%$ accepted error at $95 \%$ confidence interval using this formula: $\mathrm{N}=1.962{ }^{*} \operatorname{Pexp}(1-$ Pexp$) /$ $\mathrm{d} 2$; where, $\mathrm{N}=$ required sample; $\mathrm{Pexp}=$ expected prevalence; $\mathrm{d}=$ desired absolute precision. A total of 246 bovine were selected by simple random sampling method.

\section{Study methodology}

Regular visits were made to conduct ante mortem examination of animals brought for slaughter and during this time, individual animals were identified with regard to sex and body condition score and the results were recorded accordingly. Animals, depending on their body condition, were ranked as good, medium, and poor based on Nicholson et al. [10]. All the animals were identified on the basis of enumerated marks on their body surface using ink, and this marking was transferred to all visceral organs during postmortem inspection. Postmortem examinations were thoroughly carried out by visual inspection, palpation, and systematic incision of each visceral organ particularly the lung, liver, spleen, kidney, and heart carried out according to procedures recommended by WHO [4]. The size (diameter in centimeters) of each and individual cysts randomly selected was measured, and the number of cysts per organ was counted and recorded. The cysts randomly selected and collected from different organs were taken to the laboratory to conduct fertility and viability tests. All organs harboring hydatid cysts were partially or totally condemned and judged according to guidelines on meat inspection for developing countries [11]. According to their size, hydatid cysts were then classified as small $(<4$ $\mathrm{cm}$ ), medium $(4-8 \mathrm{~cm}$ ), and large (above $8 \mathrm{~cm}$ ) in diameter; according to Oostburg et al. [12] classification system. After each representative, hydatid cyst was randomly collected from different organs and taken to the laboratory, the cyst wall was carefully opened with scalpel blade and the contents were poured into a clean glass Petri dish and examined under a microscope $(\times 40)$ for the presence of hydatid protoscolices. If the protoscolices were present, seen as white dots on the germinal epithelium or brood capsule or hydatid sands within the suspension, the cyst was categorized as fertile. Then the fertile cysts were further subjected for viability test. A drop of the sediment consisting of the protoscolices was placed on microscope glass slide and a drop of $0.1 \%$ aqueous eosin solution was added and then covered with $22 \times 22 \mathrm{~mm}$ cover slip and observed under microscope $(\times 40)$, with the principle that viable protoscolices should completely or partially exclude the dye while the dead ones take it up [13]. Moreover, the infertile cysts were also classified as sterile or calcified according to Macpherson et al. [3].

\section{Economic analysis}

To determine the economic losses due to hydatidosis in cattle, both direct and indirect losses were considered. The calculation of the direct losses is based on condemned organs (lung, liver, heart, spleen and kidney) and the indirect losses were assessed on the basis of live weight reduction due to hydatidosis. In calculating cost of condemned edible organs and carcass weight loss, six Different meat sellers were interrogated randomly to establish the price per unit organ and the collective price of lung, liver, heart, spleen, and kidney was determined. Average price was drawn out from that data and this price index was later used to calculate the meat loss in terms of Ethiopian birr (ETB). Average annual slaughter rate of cattle in Bako municipality abattoir was estimated based on retrospective analysis of data recorded from three years. A 5\% estimated carcass weight loss due to bovine hydatidosis described by Endrias [2] was taken into account to determine the carcass weight loss. Average carcass weight of an Ethiopian zebu was taken as $126 \mathrm{~kg}$, as estimated by International Livestock Center for Africa.

\section{Direct loss from organ condemnation}

Annual economic loss $=(\mathrm{PI} 1 \mathrm{x}$ TkxC1 $)+(\mathrm{PI} 2 \mathrm{xTkxC} 2)+$ $\left(\mathrm{PI} 3 \mathrm{xTkxC}^{2}\right)+(\mathrm{PI} 4 \mathrm{xTkxC} 4)$.

Where PI1=Percent involvement of lung out of the total examined

PI2=Percent involvement of liver out of the total examined

PI3=Percent involvement of spleen out of the total examined

PI4=Percent involvement of heart out of the total examined

$\mathrm{C} 1=$ Average market price of liver

$\mathrm{C} 2=$ Averagemarketpriceoflung

$\mathrm{C} 3=$ Average market price of heart 
Citation: Haftu B, Kebede T (2014) Study on Prevalence and Economic Significance of Bovine Hydatidosis in Bako Muncipal Abattoir, West Shoa Zone, Oromiya Regional State. J Veterinar Sci Technol 5: 197. doi:10.4172/2157-7579.1000197

Page 3 of 5

\section{C4=Average market price of spleen}

$\mathrm{TK}=$ Average annual kill of bovines

\section{Indirect loss from carcass weight loss}

Annual economic losses due to carcass weight loss $=\mathrm{Ns} \times \mathrm{Ci} \times \mathrm{Pa}$ [14].

Where Ns=Total number of animals slaughtered and positive for hydatidosis; $\mathrm{Ci}=$ Carcass weight lost in individual animals; $\mathrm{Pa}=$ Average market price of a $\mathrm{kg}$ of beef in Bako; Annual economic losses were calculated by adding both direct and in direct losses

\section{Data analysis}

Data obtained from the study were analyzed using SPSS version 20 software and the magnitude of the difference of comparable variables was tested using chi-square.

\section{Results}

\section{Antemortem examination result}

Up on regular visit done on animals brought for slaughter, individual animals were assessed with regard to their place of origin, age, sex, breed and body condition and all animals were found adult, local zebu brought from the local markets of the disritct. Both, male and female animals were identified and recorded with their body condition score as good, medium and lean.

\section{Clinical examination results}

Out of the total 246 cattle slaughtered and examined during the study duration, 29(11.8\%) were found infected with hydatid cysts, harboring one or more cysts in different visceral organs (liver, lung, kidney, spleen, and heart). Analysis of the occurrence of infection with regard to body condition, and sex was made by using proportions and chi-square test. Sex did not show significant difference with regard to cyst detection ( $p>0.05$ ), but body condition shows significant difference $(\mathrm{p}<0.05)$

In this study the proportion of hydatidosis in various organs was also determined. Lungs were found to be the commonly affected organ. The total number of organs with one or more hydatid cysts was 36 and relative proportion of each organ is as follows: Lungs 17 (47.2 5), liver 14 (38.8\%), Kidney 3(8.33\%), spleen 1 (2.77\%) and heart $1(2.77 \%)$ (Table 1).

\section{Proportion of hydatidosis in different organs}

Out of 36 cysts detected from different organs, 17(47.2\%),

\begin{tabular}{|l|c|c|c|}
\hline Variables & No. examined & No. infected & Relative prevalence \\
\hline Sex & & & \\
\hline Male & 221 & 27 & 10.975 \\
\hline Female & 25 & 2 & 0.813 \\
\hline Total & 246 & 29 & 11.788 \\
\hline Body condition & & & \\
\hline Fat & 137 & 6 & 2.43 \\
\hline Medium & 87 & 12 & 4.87 \\
\hline Lean & 22 & 11 & 4.71 \\
\hline Total & 246 & 29 & 12.02 \\
\hline
\end{tabular}

Table 1: Analysis of risk factors with regard to detection of hydatid cysts in cattle slaughtered at Bako municipal abattoirs.
14(38.88\%), 1(2.77\%), 3(8.33\%) and 1(2.77\%) Were found from the lung, liver, spleen, kidney, and heart respectively (Table 2).

\section{Size distribution of cysts in relation to different organs of cattle}

Out of the total hydatid cysts recorded (36), 17(47\%) were small, 14 (38.88\%) medium, and 5(13.88) large cysts (Table 3).

\section{Cyst Status characterization}

Of the 36 hydatid cysts collected and examined for the status of fertility, sterility, or calcification, 18 (50\%) were fertile, $4(11.11 \%)$ sterile, and $14(38.88 \%)$ calcified (Table 3$)$. And out of 18 fertile cysts tested for viability, 10 (27.77\%) were viable and $8(22.22 \%)$ were nonviable (Table 4).

\section{Economic loss estimation (financial loss evaluation)}

Direct loss from organ condemnation: in the current study a total of 17 lungs (47.2\%), 14 livers (38.88\%), 1 spleen (2.77\%), 1 Heart (2.77\%) and 3 kidneys (8.33\%), were condemned due to detection of hydatid cysts. The mean current unit prices of these organs in Bako are 4.0, 65.0, 2.0, 3.0, and 8.0 ETB, respectively, while the mean current price of $1 \mathrm{~kg}$ beef is $90 \mathrm{ETB}$. Mean number of animals slaughtered annually at bako municipal abattoir was determined from the records of the last 1 year as1988. Then, the annual economic loss due to organ condemnation is estimated as follows:

Annual economic loss due to organ condemnation $=(\mathrm{PI} 1 \mathrm{x} \mathrm{TkxC} 1)+$ $(\mathrm{PI} 2 \mathrm{xTkxC} 2)+(\mathrm{PI} 3 \mathrm{xTkxC} 3)+(\mathrm{PI} 4 \mathrm{xTkxC} 4) ;(0.472 \times 1988 \times 65)+(0.388$ $\times 1988 \times 4)+(0.0277 \times 1988 \times 3)+(0.0277 \times 1988 \mathrm{X} 2)=64,349.8 \mathrm{ETB}$

\begin{tabular}{|c|c|c|}
\hline Organ & No. positive & Relative prevalence (\%) \\
\hline Lung & 17 & 47.2 \\
\hline Liver & 14 & 38.88 \\
\hline Spleen & 1 & 2.77 \\
\hline kidney & 3 & 8.33 \\
\hline heart & 1 & 2.77 \\
\hline Total & 36 & 100 \\
\hline
\end{tabular}

Table 2: Shows the relative distribution of the cysts in different organs of the cattle's.

\begin{tabular}{|l|c|c|c|c|c|}
\hline \multirow{2}{*}{ Cyst type } & \multicolumn{5}{|c|}{ Organs inspected } \\
\cline { 2 - 6 } & Lung & Liver & Spleen & Kidney & Heart \\
\hline Small & $4(23.5 \%)$ & $12(70.5 \%)$ & --- & $1(5.88 \%)$ & -- \\
\hline Medium (7.14\%) & $9(64.28 \%)$ & $2(14.28 \%)$ & $1(7.14 \%)$ & $1(7.14 \%)$ & -- \\
\hline Large & $4(80 \%)$ & --- & --- & $1(20 \%)$ & --- \\
\hline Total & 17 & 14 & 1 & 3 & 1 \\
\hline
\end{tabular}

Table 3: Size and organ distribution of haydatid cyst at bako municipal abattoir during the study period.

\begin{tabular}{|c|c|c|c|c|c|}
\hline \multirow{2}{*}{$\begin{array}{c}\text { Examined } \\
\text { organs }\end{array}$} & $\begin{array}{c}\text { No. of } \\
\text { cysts } \\
\text { examined }\end{array}$ & \multicolumn{2}{|c|}{ Vertile } & Sterile (\%) & \\
\hline Lung & 17 & $8(47.05 \%)$ & $6(35.2 \%)$ & $2(11.76 \%)$ & $1(5.88 \%)$ \\
\hline Liver & 14 & $1(7.14 \%)$ & --- & --- & $13(92.86 \%)$ \\
\hline Kidney & 3 & $1(33.33 \%)$ & $1(33.33 \%)$ & $1(33.33 \%)$ & --- \\
\hline Spleen & 1 & --- & $1(100 \%)$ & -- & -- \\
\hline Heart & 1 & --- & --- & $1(100 \%)$ & --- \\
\hline Total & 36 & 10 & 8 & 4 & 14 \\
\hline
\end{tabular}

Table 4: Status of cysts in different organs of cattle slaughtered at Bako municipal abattoir. 
Meat production loss: Annual economic losses due to carcass weight loss $=\mathrm{Ns} \times \mathrm{Ci} \times \mathrm{Pa}$ (Polydorou, 1981).

$=29 \times 5 \% \times 126 \times 90$

$=29 \times 0.05 \times 126 \times 90$

\section{$=16,443 E T B$}

Annual economic loss=Annual economic losses due to organ condemnation+Annual economic losses due to carcass weight loss.

Annual economic loss $=64,349 \mathrm{ETB}+116,443 \mathrm{ETB}=180,792 \mathrm{ETB}$.

Hence, the total loss from organ condemnation and meat production loss in cattle slaughtered at bako municipal abattoir is estimated at 180,792 ETB.

\section{Discussion}

This study revealed that the prevalence of hydatidosis in cattle slaughtered at bako municipal abattoir was $11.8 \%$. This finding is closer to that reported as $15.4 \%$ by Regassa et al. [15] and $16 \%$ by Kebede et al. [16]. However, it is lower than the findings from different places in Ethiopia like 61\% in Assela [17], 52.69\% in Hawassa [15], 48.9\% in Debre Markos [16], 46.5\% in Debre Zeit [18], 34.05\% in Bahir Dar [19], $32.1 \%$ in Mekelle [8], and 22\% in Tigray [20]. Factors like difference in culture, social activity, animal husbandry systems, lack of proper removal of infectious carcass, and attitude to dogs in different regions might have contributed to the variation in prevalence in different areas of a country [21,22].

In this study, an assessment was made to establish relationship between body condition scores and hydatid cyst count. Animals with poor body condition were found to have higher hydatid cyst count and the poor condition among animals is probably a reflection of the effect of relatively high cyst burden. Polydorou [14] explained that in moderate to sever infection, the parasite may cause retarded performance and growth, reduced quality of meat and milk, as well as live weight loss.

No significant variation was noticed with regard to sex of animals. This may be explained by indiscriminate exposure to risk irrespective of sex in the management system of the area.

In this study, it has been shown that hydatid cysts occurred most commonly in the lung (47.2\%) followed by the liver (38.88\%), kidney $(8.33 \%)$, and $(2.77 \%)$ in spleen and heart. This is in agreement with the findings of Njoroge et al. [23] and Eckert and Deplazes [6], which show that the lung and liver are the most common sites of hydatid cyst in domestic animals. It is due to the fact that the lung and liver posses first great capillaries encountered by the migrating echinococcus oncosphere (hexacanth embryo), which adopt the portal vein route and primarily negotiate hepatic and pulmonary filtering system sequentially before any other peripheral organ is involved. Likewise, due to older age of slaughtered cattle, during which time the liver capillaries are dilated and most oncosphere pass directly; additionally, it is possible for the hexacanth embryo to enter the lymphatic circulation and be carried through the thoracic duct to the lungs in such a way the lung may be infected before or instead of the liver [6].

A greater frequency of medium-sized and large-sized cysts was found in the lung than in the liver, while the liver harbored a large number of small-sized and calcified cysts. The reason for the higher percentage of medium and large cysts in the lungs is the softer consistency of the lung, while the higher number of calcified cysts in liver could be attributed to relatively higher reticuloendothelial cells and abundant connective tissue reaction of the organ. The higher proportion of small cysts may be due to immunological response of host which might preclude expansion of cyst size $[24,25]$. In examining the condition of cyst fertility and viability, the overall percentage of fertile cysts in this study was (50\%). This is in agreement with the finding of Kebede et al. [20] but higher than the finding of Kebede et al. [16]. In the comparison of the fertility rate among the organs, it was higher in the lungs than in the liver. It has been stated that the relatively softer consistency of lung tissue allows the easier development of the cyst, and the fertility rate of hydatid cysts may show a tendency to increase with advancing age of the hosts [26]. This may be attributed probably due to reduced immuno-logical compatibility of animals at their older age of infection. The variation between tissue resistances of the infected organs may also influence the fertility rate of hydatid cysts.

The fertility rates observed in this study in all infected animals highlight the hazard that these animals perpetuate the cycle of hydatidosis when slaughtered and when raw offal are fed to dogs and also leftovers during backyard slaughter are eaten by wild carnivores. It was observed that majority of households had livestock including cattle, sheep, goat, and donkeys, which are the intermediate host of the parasite. Similarly, many households had dogs and cats, which were not dewormed regularly and were managed under free-range system. This study also revealed that a higher proportion of the cysts were fertile (50\%) and calcified (38.88\%). In the current study, it was emphasized to carry out an assessment on annual economic loss due to bovine hydatidosis at bako municipal abattoir. Losses from organ condemnation and carcass weight loss (meat production loss) in infected cattle were assessed and estimated at 180,792 ETB. The current estimate is approximately greater than $(25,608 \mathrm{ETB})$ that estimated by Kebede et al. [20] in Tigray region. However, it is lower than 1,791,625.89 ETB that estimated by Regassa et al. [15] in Hawassa municipal abattoir. The difference in economic loss estimates in various abattoir/regions may be due to the variations in the prevalence of disease, mean annual number of cattle slaughtered in different abattoirs, and variation in the retail market price of organs. Considering the current result, hydatidosis is an important disease of cattle in bako and its surroundings, causing substantial visible and invisible losses. It causes considerable economic loss in livestock due to condemnation of organs and denied weight gain of infected stocks.

\section{Acknowledgements}

Special thanks to Wollega University, Nekemte, Ethiopia fully financial funded for this research.

\section{References}

1. Craig PS, McManus DP, Lightowlers MW, Chabalgoity JA, Garcia HH, et al (2007) Prevention and control of cystic echinococcosis. Lancet Infect Dis 7: 385-394.

2. Endrias Z, Yechale T, Assefa M (2010) Bovine Hydatidosis in Ambo Municipality Abattoir, West Shoa, Ethiopia Ethiop Vet J 14: 1-14.

3. Macpherson CN, Zeyhle E, Romig T (1984) An Echinococcus pilot contro programme for north-west Turkana, Kenya. Ann Trop Med Parasitol 78: 188192.

4. World Health Organisation (2002) WHO/OIE Manual on Echinococcosis in Humans and Animals: a Public Health Problem of Global Concern, Eckert J., Gemmell, M.A, Meslin FX, Pawlowski ZS, eds. OIE (World Organisation for Animal Health, Paris, France, 1-286.

5. Hagos B, Mesfin M, Abebe B (2006) Hydatid disease of the liver: A 12 year experience of surgical management. East And Central African Journal of Surgery 11: 54-60.

6. Eckert J, Deplazes P (2004) Biological, epidemiological, and clinical aspects of echinococcosis, a zoonosis of increasing concern. Clin Microbiol Rev 17: 107-135. 
Citation: Haftu B, Kebede T (2014) Study on Prevalence and Economic Significance of Bovine Hydatidosis in Bako Muncipal Abattoir, West Shoa Zone, Oromiya Regional State. J Veterinar Sci Technol 5: 197. doi:10.4172/2157-7579.1000197

Page 5 of 5

7. Kebede W, Hagos A, Girma Z, Lobago F (2009) Echinococcosis/hydatidosis: its prevalence, economic and public health significance in Tigray region, North Ethiopia. Trop Anim Health Prod 41: 865-871.

8. Berhe G (2009) Abattoir survey on cattle hydatidosis in Tigray Region of Ethiopia. Trop Anim Health Prod 41: 1347-1352.

9. Thrusfield M (2005) Veterinary epidemiology, 3rd edition. United Kingdom. Blackwell Sciences Ltd. 626.

10. Nicholson M, Butterworth M (1986) A guide to condition scoring of zebu cattle. International Livestock Centre for Africa, Addis Ababa, Ethiopia.

11. Herenda D, Chambers P, Ettriqui A, Seneviratna P, DaSilva J (1994) Manual on meat inspection for developing countries. FAO, Rome, 160-164.

12. Oostburg BF, Vrede MA, Bergen AE (2000) The occurrence of polycystic echinococcosis in Suriname. Ann Trop Med Parasitol 94: 247-252.

13. Dalimi A, Motamedi G, Hosseini M, Mohammadian B, Malaki H, et al. (2002) Echinococcosis/hydatidosis in western Iran. Vet Parasitol 105: 161-171.

14. Polydorou K (1981) Animal health and economics. Case study: echinococcosis with reference to Cyprus. Bulletin, Office International des Epizooties 93: 981 -

15. Regassa F, Molla A, Bekele J (2010) Study on the prevalence of cystic hydatidosis and its economic significance in cattle slaughtered at Hawassa Municipal abattoir, Ethiopia. Trop Anim Health Prod 42: 977-984.

16. Kebede N, Mekonnen H, Wossene A, Tilahun G (2009) Hydatidosis of slaughtered cattle in Wolaita Sodo Abattoir, southern Ethiopia. Trop Anim Health Prod 41: 629-633.

17. Koskei $P$ (1998) Prevalence and strain differentiation of Echinococcus granulosus in some selected sites of Ethiopia. Berlin and Ethiopia: Ferie Universitat and Addis Ababa University, M.Sc. thesis.

18. Jobre Y, Labago F, Tiruneh R, Abebe G, Dorchies $P$ (1996) Hydatidosis in three selected regions of Ethiopia: an assessment trail on the prevalence, economic and public health importance. REVUE de Médecine Vétérinaire, 147: 797-804.

19. Kebede N, Mitiku A, Tilahun G (2009) Hydatidosis of slaughtered animals in Bahir Dar Abattoir, Northwestern Ethiopia. Trop Anim Health Prod 41: 43-50.

20. Kebede W, Hagos A, Girma Z, Labago F (2009c) Echinococcosis/hydatidosis: its prevalence, economic and public health significance in Tigray region, North Ethiopia. Tropical Animal Health and Production 41: 865-871.

21. Arene FOI (1985) Prevalence of hydatidosis in domestic livestock in the Niger Delta. Tropical Animal Health and Production 17: 3-4

22. Garippa G, Varcasia A, Scala A (2004) Cystic echinococcosis in Italy from the 1950s to present. Parassitologia 46: 387-391.

23. Njoroge EM, Mbithi PM, Gathuma JM, Wachira TM, Gathura PB, et al. (2002) A study of cystic echinococcosis in slaughter animals in three selected areas of northern Turkana, Kenya. Vet Parasitol 104: 85-91.

24. Lahmar S, Kilani M, Torgerson PR, Gemmell MA (1999) Echinococcus granulosus larvae in the livers of sheep in Tunisia: the effects of host age. Ann Trop Med Parasitol 93: 75-81.

25. Torgerson $P$ (2002) Transmission dynamics of taeniid parasite animal hosts. In: P. Craig and Z. Pawlowski (ed.), Cestode zoonoses: echinococcosis and cysticercosis, an emergent an global problem. The Netherlands, Amsterdam. IOS press, 221-235.

26. Himonas C (1987) The fertility of hydatid cyst in food animals in Greece. Helminth zoonoses. Martinus Nijjhof Publishers, 12-17. 